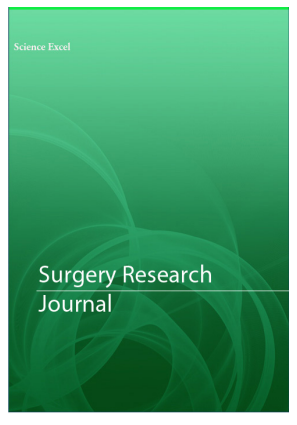

Correspondence

Tomas Edgar Benavides-Zaval MD

Service of General Surgery, Hospital Universitario "Dr. José Eleuterio González", Universidad Autónoma de Nuevo León, Av. Francisco I. Madero s/n, Col. Mitras Centro, CP. 66460, Monterrey, Nuevo León, Mexico E-mail: rodolfot59@hotmail.com

- Received Date: 03 Feb 2021

- Accepted Date: 09 Mar 2021

- Publication Date: 13 Mar 2021

Keywords

Subcutaneous closure, post-surgical complications, surgical wound, sutures

\section{Copyright}

(c) 2021 Science Excel. This is an openaccess article distributed under the terms of the Creative Commons Attribution 4.0 International license.

\title{
Use of Absorbable Suture in Subcutaneous Cell Tissue and Its Impact On The Reduction of Collections in Abdominal Surgical Wounds Experience At The University Hospital "Dr. José Eleuterio González"
}

\section{Tomas Edgar Benavides-Zavala*, José Angel Rodriguez-Briseño, Gerardo Enrique Muñoz.Maldonado, Ervey Alexis Benavides-Zavala, Aarón Abelardo Gándara-Hernández}

Service of General Surgery, Hospital Universitario "Dr. José Eleuterio González", Universidad Autónoma de Nuevo León, Monterrey, Nuevo León, Mexico

\begin{abstract}
Introduction: Sutures most commonly provide mechanical support for the closed wound during its initial healing. They approximate the wound edges and help maintain wound closure until the healing process provides sufficient force for the wound to withstand stress and strain.

Materials and methods: Retrospective, descriptive, comparative and observational study. It was carried out in the general surgery service of the University Hospital 'Dr José Eleuterio González" where cases of 30 patients who underwent uncontaminated abdominal surgical procedures in the period of time between January 2020 - September 2020 were analyzed.

Results: The average hospital stay of all patients was $11 \pm 3.1$ days. The participants in group A showed a mean of $11.2 \pm 3.4$ days, while those in group B showed a mean of $10.9 \pm 2.9$ days without showing a significant difference between both study groups. In group A, $4(25 \%)$ of the patients showed seroma, while $12(75 \%)$ did not, while in group B $4(28.5 \%)$ showed seroma, and $10(71.5 \%)$ did not.

Conclusion: The use of subcutaneous cellular tissue closure with absorbable suture did not show any benefit or harm in those patients who underwent it, so there was no decrease in the incidence of seroma, wound dehiscence, or decrease in hospital stay compared to other methods used.
\end{abstract}

\section{Introduction}

The function of the suture is to restore anatomical relationships so that healing occurs optimally. It is not known for sure what the healing process is like, in fact we cannot improve it in cases where effective healing is needed, nor can we stop it when hypertrophic and keloid wounds form; thus, the less an uncomplicated wound is touched, the better its cosmetic result and the lower the risk of complications. Some surgeons recommend subcutaneous suturing, claiming that it decreases wound complications, while others think it is unnecessary and may increase wound complications.

Laparotomy is a surgical incision that is used to access the organs of the abdominal cavity and is one of the most common surgical procedures performed worldwide. Sutures most commonly provide mechanical support for the closed wound during its initial healing [1]. They approximate the edges of the wound and help maintain wound closure until the healing process provides sufficient force for the wound to withstand stress and strain. For most surgeons, the choice of suture material in a given case is primarily due to exposure to training and local opinion, and many surgeons are reluctant to try different techniques once their personal preferences have been established $[1,2]$.

Surgeons affect the skin in most surgical procedures. Complications of abdominal wall closure are common and include seroma, hematomas, surgical site infection (SSI), dehiscence, positional hernia, and granuloma formation. Most surgical wounds are sutured flat at the end of the procedure. The skin is the outermost layer of tissue in the human body, and the subcutaneous tissue is just below it [3]. The use of sutures in the subcutaneous tissue after surgery is controversial. Some surgeons recommend it and claim that it decreases wound complications, while others think it is unnecessary and may increase wound complications including suture-associated infections. Currently there is very low quality evidence that is insufficient to support or reject subcutaneous closure (SCC) after exploratory laparotomy. The use of the SCC has the potential to affect patient outcomes and utilization of healthcare resources. Additional well-designed trials with low risk of bias are needed $[4,5]$. 
In other anatomical parts of the body, it has been proven that the closure of the subcutaneous cellular tissue reduces the risk of the appearance of collections, as is the case with inguinal plasties in comparison with compression bandages and in neck surgeries such as cervicotomies. In a plastic surgery study in which they performed Scarpa's fascia closure after performing abdominal liposuctions and abdominoplasties, they found that the closure of Scarpa's fascia with absorbable suture was related to a decrease in the formation of seromas in its equivalent to the use of drains in surgical bed. It is believed that when performing a simple suture on subcutaneous cellular tissue, the dead space between the tissues decreases and this favors healing and decreases the formation of collections: There are those who argue that said closure increases wound infection due to the increase in inflammation in the area due to the reaction to a foreign body of the suture with the subsequent colonization of bacteria and SSI, all this without current scientific verification [6].

The objective of this study was to determine and compare the advantages and disadvantages of closing subcutaneous cellular tissue with absorbable suture in uncontaminated abdominal surgical wounds. The hypothesis was that the closure of subcutaneous cellular tissue with absorbable suture reduces the formation of seromas in uncontaminated abdominal surgical wounds.

\section{Method}

Retrospective, descriptive, comparative and observational study. It was carried out in the general surgery service of the University Hospital "Dr José Eleuterio González" where cases of 72 patients who underwent uncontaminated abdominal surgical procedures in the period of time between January 2020 - September 2020 were analyzed.

The inclusion criteria that were integrated to carry out this study were: Patients older than 18 years of age, gender indistinct, patients who underwent uncontaminated abdominal surgical wounds, patients that did not represent data on abdominal peritonitis or sepsis, patients hemodynamically stable, patients with adipose pad greater than $1 \mathrm{~cm}$, patients dependent on mechanical ventilation, patients who speak the Spanish language. Exclusion criteria were: patients with data of bacterial peritonitis or abdominal sepsis, hemodynamic instability, need for immediate mechanical ventilation, patients with an adipose pad less than $1 \mathrm{~cm}$ thick, patients who underwent a contaminated abdominal surgical wound and surgical wounds by laparoscopic ports. The elimination criteria used were: incomplete data in the collection sheet and those patients who refused to participate in the study.

The description of the design of this study consisted starting with an analysis of the variables obtained such as weight, body mass index, type II diabetes mellitus, systemic arterial hypertension, dyslipidemias, preoperative diagnosis, type of surgery and wound closure technique. The records were kept by means of folio without using the name or record of the patients for data management and said folios were linked with the name of the patients in a list that was kept by the main investigator without access for the rest of the team research, adjusting to current data protection laws.

In the analysis of qualitative variables, the Chi-square test or Fisher's exact test was used in the case of independent groups. For the quantitative variables, they were evaluated with a student's T of independent samples for parametric distribution and Mann Whitney's $U$ test for non-parametric distribution. A value of $\mathrm{p}<0.05$ was taken as statistically significant. SPSS version 21 was used to perform the statistical analysis.

\section{Results}

The study consisted of 72 patients in such a way that they were divided into 2 groups: Group A which included patients where subcutaneous closure was performed after their operation (37 participants) and Group B where patients were classified without subcutaneous closure (35 participants). Of the 72 patients studied, 48 (66.6\%) were men and the remaining $24(33.3 \%)$ were women. Of the 37 members of group A, 23 $(62.2 \%)$ were men and $14(37.8 \%)$ were women, while in group B $22(62.8 \%)$ of the participants were men and the remaining $13(37.2 \%)$ were women.

The age of the patients in general obtained an average of 41.23 \pm 10.64 years. In group A, a mean age of $39.94 \pm 11.83$ years was shown, while in group B the mean age was $42.71 \pm 9.30$ years, $\mathrm{p}=0.22$, not significant.

Of the pathological personal antecedents most commonly presented in the general population, the most frequent was being overweight, showing up in 38 (52.7\%) of the participants. In group $\mathrm{A}$, as in the general population, overweight was the most common in $14(37.8 \%)$ of the cases, $9(24.3 \%)$ of the patients were obese, $11(29.7 \%)$ were reported with DM II , and only $2(5.4 \%)$ were hypertensive. In group B, 15 (42.8\%) were overweight, 10 (28.5\%) were obese, another 10 (28.5\%) showed DM II, as well as the remaining 7 (20\%) had hypertension (Table 1)

Within the non-pathological personal antecedents, it was reported that in group A $16(43.2 \%)$ consumed tobacco, 11 (29.7\%) had alcoholism while $9(24.3 \%)$ did not have any nonpathological personal history (NPPH). In group B 10 (28.5\%) people used to smoke tobacco, 7 (20\%) had alcoholism, while the remaining $16(45.7 \%)$ patients did not show any NPPH (Table 2).

The average hospital stay of all patients was $11 \pm 3.1$ days. Participants in group A showed a mean of $11.2 \pm 3.4$ days, while those in group B showed a mean of $10.9 \pm 2.9$ days without showing a significant difference between both study groups. $\mathrm{p}$ $=0.45$, not significant.

The most frequent surgical wound at the time of preparing this study was the clean wound, which was made in 43 (59.7\%) of the occasions, while the remaining 29 (40.3\%) were cleancontaminated wounds, speaking of the population. usually. From group A, the type of surgical wound that was performed more frequently was clean, being carried out on $21(56.7 \%)$ occasions, and clean-contaminated wounds were performed on $16(43.3 \%)$ occasions. In group B on $22(62.8 \%)$ occasions the surgical wound was clean, while in $13(37.2 \%)$ it was cleancontaminated.

It was recorded whether there was a collection in the total population, where $19(26.4 \%)$ showed seroma, while the remaining $53(73.6 \%)$ patients did not develop any collection. From group A, 9 (24.3\%) of the patients showed seroma, while $28(75.7 \%)$ did not, while from group B 10 (28.6\%) showed seroma, and 25 (71.4\%) did not. The reported results did not show significant differences between both groups.

In addition to seroma, other complications observed in the patients were reported, such as fever and wound dehiscence. In group A, fever was reported in $5(13.5 \%)$ of the patients, in the same way that in $5(13.5 \%)$ of them, wound dehiscence was shown, while the remaining 27 (73\%) did not report any other complication. In group B, 5 (14.3\%) of the patients developed fever, while only in 2 (5.7\%) patients was wound dehiscence observed, on the other hand, the remaining 28 (80\%) patients did not show any other complication. No significant differences were observed with the results of both groups. 
Table 1. Pathological personal history

\begin{tabular}{|c|c|c|}
\hline \multicolumn{3}{|c|}{ PATHOLOGICAL PERSONAL HISTORY: Group A } \\
\hline Background & Total patients & Percentage \\
\hline Overweight & 14 & $37.8 \%$ \\
\hline Obesity & 9 & $24.3 \%$ \\
\hline DMII & 11 & $29.7 \%$ \\
\hline Arterial hypertension & 2 & $5.4 \%$ \\
\hline \multicolumn{3}{|c|}{ PATHOLOGICAL PERSONAL HISTORY: Group B } \\
\hline Total patients & Total patients & Total patients \\
\hline Overweight & 15 & $42.8 \%$ \\
\hline Obesity & 10 & $28.5 \%$ \\
\hline DMII & 10 & $28.5 \%$ \\
\hline Arterial hypertension & 7 & $20 \%$ \\
\hline
\end{tabular}

Table 2. Non-pathological personal history

\section{NON-PATHOLOGICAL PERSONAL HISTORY: Group A}

\begin{tabular}{|c|c|c|}
\hline Background & Total patients & Percentage \\
\hline Smoking & 16 & $43.2 \%$ \\
\hline Alcoholism & 11 & $29.7 \%$ \\
\hline Without NPPH & 9 & $24.3 \%$ \\
\hline \multicolumn{3}{|c|}{ NON-PATHOLOGICAL PERSONAL HISTORY: Group B } \\
\hline Background & Total patients & Percentage \\
\hline Smoking & 10 & $28.5 \%$ \\
\hline Alcoholism & 7 & $20 \%$ \\
\hline Without NPPH & 16 & $45.7 \%$ \\
\hline
\end{tabular}

\section{Conclusions}

The use of subcutaneous cell tissue closure with absorbable suture did not show any benefit or harm in those patients who underwent it, so there was no decrease in the incidence of seroma, wound dehiscence, or reduction in stay hospital compared to other methods used.

Since mortality is unlikely to be affected by the use (or non-use) of subcutaneous closure, quality of life and costs will be the main factors determining which intervention is recommended by health funders.

\section{References}

1. Díaz R, Ortíz C, Marinkovic B, Jerez O, D’Aguzan N, Turu M. Midline laparotomy technique consensus using the Delphi method. Rev Cir. 2019;71(4):307-317.

2. Thörbeck RV, Olmo FJJ. Los cierres problemáticos de la cavidad abdominal. Seminario médico. 2001;53(1):84-99.

3. Ferreira P, Oría A. Heridas y cicatricación. C. 5ta ed. Buenos Aires. El ateneo. 2008;143-147.

4. Álvarez J, Porrero JL, Dávila D. Cierre de laparotomía. Cirugía de la pared abdominal. 2da ed. Madrid. Editorial Arán. 2003;3138.

5. Gurusamy KS, Toon CD, Davidson BR. Subcutaneous closure versus no subcutaneous closure after non-caesarean surgical procedures. Cochrane Database Syst Rev. 2014;(1):CD010425.

6. del Mónaco D, Anthony R. Técnicas novedosas en el cierre de piel y tejido celular subcutáneo en distintos procesos quirurgicos. Un estudio comparativo prospectivo entre grapas absorbibles sub dérmicas y uso manual de sutura de nylon en procesos quirugicos. Univ Guayaquil. 2015;1-26.

7. Cardosi RJ, Drake J, Holmes S, et al. Subcutaneous management of vertical incisions with 3 or more centimeters of subcutaneous fat. American Journal of Obstetrics and Gynecology 2006;195(2):607-14.

8. el Gamel A, Dyde J, Perks J, Shaw R. Should we stitch the subcutaneous fat layer following saphenous vein excision for coronary revascularization?. European Journal of CardioThoracic Surgery 1994;8(3):162-4.

9. Hussain SA. Closure of subcutaneous fat: a prospective randomized trial. British Journal of Surgery 1990;77(1):107.

10. Kore S, Vyavaharkar M, Akolekar R, Toke A, Ambiye V. Comparison of closure of subcutaneous tissue versus nonclosure in relation to wound disruption after abdominal hysterectomy in obese patients. Journal of Postgraduate Medicine 2000;46(1):268 .

11. Tamelis A, Vanagas T, Saladzinskas Z, Toker I, Pavalkis D. Do the fat stitch impacts on the superficial complications rate after midline incision?. Colorectal Disease 2005;7 (Supplement S2):61.

12. Tiryakioglu O, Goncu T, Yumun G, et al. Unilayer closure of saphenous vein incision lines is better than bilayer closure. Open Cardiovascular Medicine Journal 2010;4:293-6. 